\title{
PRODUCCIÓN DE ETANOL A PARTIR DE YUCA FRESCA UTILIZANDO LA ESTRATEGIA DE PROCESO HEFS (HIDRÓLISIS ENZIMÁTICA Y FERMENTACIÓN SIMULTÁNEAS) USANDO ENZIMAS REDUCTORAS DE VISCOSIDAD
}

\author{
Hader Iván Castaño-Peláez ${ }^{1}$ \\ ${ }^{1}$ Docente - investigador Politécnico Colombiano Jaime Isaza Cadavid. \\ Correo de correspondencia: hicastano@elpoli.edu.co
}

\section{RESUMEN}

Se evaluó la producción de etanol a partir de yuca fresca mediante el uso de enzimas reductoras de viscosidad y enzimas hidrolizantes de almidón en forma granular utilizando la estrategia de proceso de integración en forma simultánea de la hidrólisis y la fermentación. Se utilizaron tubérculos de yuca fresca; se evaluó el efecto del $\mathrm{pH}$, carga enzimática y la cáscara sobre la viscosidad; se evaluó además el prelicuado de los gránulos de almidón y el efecto de la carga del complejo Stargen® 01 y el inoculo sobre la producción de etanol. Se realizó la optimización y validación del proceso. El pH, actividad enzimática y la presencia de cascara presentaron efecto sobre la viscosidad; en el sistema HEFS el inóculo y la carga enzimática tuvieron efecto sobre la producción de etanol. Fue posible la producción de etanol mediante el uso de las enzimas degradantes de la pared celular para disminuirla viscosidad y mediante el uso de enzimas hidrolíticas de los gránulos de almidón.

Palabras clave: Etanol; yuca fresca; hidrolisis enzimática y fermentación simultánea (HEFS); reducción de viscosidad.

Recibido: 04 de Septiembre de 2019. Aceptado: 11 de Mayo de 2020

Received: September 04, 2019. Accepted: May 11, 2020

\section{ETHANOL PRODUCTION FROM FRESH CASSAVA USING THE PROCESS STRATEGY (SIMULTANEOUS HYDROLYSIS ANF FERMENTATION) USING VISCOSITY REDUCING ENZYMES}

\begin{abstract}
The production of ethanol from fresh cassava was evaluated by the use of viscosity reducing enzymes and starch hydrolyzing enzymes in granular form using the strategy of simultaneously integrating hydrolysis and fermentation. Cassava tubers were used; the effect of $\mathrm{pH}$, enzyme load and shell on viscosity was evaluated; In addition, the pre-liquefaction of starch granules and the effect of loading of the stargen $\Theta 01$ complex and the inoculum on ethanol production were evaluated. The optimization and validation of the process was carried out. The $\mathrm{pH}$, enzymatic activity and the shell had an effect on viscosity; In the HEFS system the inoculum and the enzymatic load had an effect on ethanol production. It was possible to produce ethanol by using degrading enzymes of the cell wall to reduce viscosity and by using hydrolytic enzymes of starch granules
\end{abstract}

Keywords: Ethanol; Fresh cassava tuber; simultaneous enzymatic hydrolysis and fermentation (SSF); viscosity reduction.

Cómo citar este artículo: H. Castaño. "Producción de etanol a partir de yuca fresca utilizando la estrategia de proceso HEFS (hidrólisis enzimática y fermentación simultáneas) usando enzimas reductoras de viscosidad", Revista Politécnica, vol.16, no.31 pp.19-28, 2020. DOI: 10.33571/rpolitec.v16n31a2 


\section{INTRODUCCIÓN}

China y Tailandia son los líderes mundiales en la producción de etanol a partir de yuca gracias al desarrollo de sus propios procesos tecnológicos. Varias formas de la yuca, que incluyen los tubérculos frescos, chips secos y almidón, pueden ser usadas industrialmente como materia prima para la producción de bioetanol. En países subtropicales la mejor forma de materia prima son los chips de yuca secados al sol; también se usan almidón y harina, pero no son competitivos por los costos incurridos en su procesamiento; mientras que los tubérculos frescos están disponibles únicamente en los países subtropicales en ciertos periodos del año. En el caso de los países tropicales como Colombia la oferta de yuca fresca se mantiene durante casi todo el año; existe en este caso limitantes como el régimen de lluvias, el nivel de perecibilidad del tubérculo (3 días) y la programación de las siembras [1,2]; éstos elementos deben ser estudiados a nivel logístico para garantizar el aprovisionamiento seguro a la planta de producción.

Wichitchan y Skolpap (2014) evaluaron las proporciones óptimas de materia prima en forma de chips y tubérculos de yuca fresca en una planta industrial de etanol en Tailandia de 340.000 l/día utilizando herramientas de programación lineal, se tuvieron en consideración los costos de materia prima, su estacionalidad, almacenamiento, transporte y conservación en un ejercicio de evaluación de un año. El costo de yuca fresca fue la tercera parte de los chips de yuca, sin embargo el rendimiento de producción de etanol a partir de yuca fresca fue el $50 \%$ del obtenido a partir de chips, debido a problemas de viscosidad e ineficiencias en la extracción de los gránulos de almidón

Las operaciones de proceso involucradas en la obtención de etanol a partir de yuca dependerán del tipo de materia prima a utilizar, chips o tubérculos de yuca y la selección de la fuente depende de la estacionalidad de los tubérculos de yuca. Existen dos variantes de proceso para la producción a partir de chips, "molienda en seco" y "molienda en húmedo". En el proceso de molienda en seco los chips son llevados a una banda donde se retiran piedras y metales, los chips son molidos y tamizados hasta obtener un polvo fino (harina de yuca [2,3]. La adición de agua a la masa de yuca fresca reduce la viscosidad, sin embargo también reduce la concentración de azucares en el fermentador, y requiere mayor energía para la separación del etanol [4]. Con el desarrollo de la tecnología enzimática es posible usar enzimas reductoras de viscosidad que posibiliten sortear las limitaciones tecnológicas de la viscosidad del sistema. Una solución práctica a esta restricción en el caso de los granos almidonáceos, ha sido el uso de enzimas degradantes de la pared celular (celulasas, hemicelulasas y pectinasas) que permiten reducir la viscosidad de las suspensiones [5].

Sirohth y Piyachomkwan (2010) reportaron el uso de enzimas reductoras de viscosidad que pueden utilizarse para mejorar la eficiencia de mezclado durante la integración de los procesos de hidrólisis y de fermentación en los procesos de producción de etanol a partir de chips. Se reportan como enzimas reductoras de viscosidad, las enzimas pertenecientes a los grupos celulasas, hemicelulasas y pectinasas. Niveles bajos de viscosidad pueden alcanzarse mediante la hidrolisis enzimática de la matriz de la pared celular. El uso de preparaciones enzimáticas de celulasas y pectinasas se han reportado en la reducción de la viscosidad en los procesos de obtención de azúcar de caña y remolacha [6], y procesamiento de vegetales y papa [7], pero no han sido evaluadas en la producción de etanol a partir de yuca fresca.

El proyecto tiene por objetivo evaluar la producción de etanol a partir de yuca fresca mediante el uso de enzimas reductoras de viscosidad y enzimas hidrolizantes de almidón en forma granular utilizando la estrategia de proceso de integración en forma simultánea de la hidrólisis enzimática y la fermentación (HEFS).

\section{MATERIALES Y MÉTODOS}

Como microorganismo fermentativo de utilizó levadura Saccharomyces cerevisiae marca Ethanol Red, una levadura osmotolerante, termófila y etanol resistente adecuada para procesos con alto contenido de sólidos. La levadura fue donada por la empresa Fermentis; y antes de ser utilizada se activó por espacio de 6 horas en medio YM con una concentración de glucosa de $30 \mathrm{~g} / \mathrm{L}$ a una temperatura de $30^{\circ} \mathrm{C}$ en shaker orbital a $100 \mathrm{rpm}$ con control de temperatura. 
Como complejos enzimáticos reductores de viscosidad se utilizaron mezclas de las siguientes enzimas: Accelerasse $\AA 1500$ con actividad endoglucanasa $2150 \mathrm{CMC} / \mathrm{g}$, actividad $\beta$ gluconasa de 630 PNPG /g, Optimash TBG con actividad endoglucanasa $4850 \mathrm{U} / \mathrm{g}$ y la enzima Pectinex Ultra SP-L con actividades pectinliasa 10320 PECT $\mathrm{u} / \mathrm{ml}$. A cada uno de los lotes de enzimas se les determinaron las actividades catalíticas según recomendaciones de los fabricantes. Se utilizó el complejo enzimático Stargen® 001570 AGU/g para realizar la hidrolisis del almidón granular.

\subsection{Caracterización química de las masas de yuca}

Las masas de yuca pelada y sin pelar fueron caracterizadas mediante la determinación de las propiedades de interés en el proceso: humedad método oficial 930.15/90 de la AOAC, proteínas método AOAC 955.04/90, cenizas método AOAC 942.05/90 [8] y almidón técnica usada por Mestres 1993 [9].

\subsection{Preparación de la masa de yuca}

Yuca Copiblanca, variedad doble propósito cultivada en el Urabá fue comprada a cultivadores locales y transportada hasta Medellín; se lavó con agua potable para retirar tierra y pantano y se sometió a desinfección con Citrosan $\AA$. Se garantizó la eliminación de la cascarilla. Se procedió al pelado manual de algunos tubérculos, los demás conservaron su cáscara; posteriormente se trocearon en cubos de aproximadamente $1 \mathrm{~cm}$ de arista, y se maceraron con molino de atrición marca Victoria. Las masas de yuca fueron conservadas en congelación a $-18^{\circ} \mathrm{C}$ hasta su uso. Las suspensiones de yuca fueron preparadas con soluciones tampón de ácido cítrico y citrato de sodio para $\mathrm{pH} 4.0$ y 5.0 en concentraciones de almidón de $15 \%$ y $25 \%$ p/v. Las unidades experimentales fueron erlenmeyer de $250 \mathrm{ml}$ con un volumen de uso de $150 \mathrm{ml}$.

\subsection{Evaluación de la reducción de la viscosidad de las suspensiones de yuca usando enzimas degradantes de la pared celular}

La viscosidad aparente de las suspensiones de yuca fresca fue evaluada con el uso de un reómetro Brookfield DV-III Ultra acoplado con un baño termostatado marca Brookfield modelo TC-502, temperatura: $25 \cong \mathrm{C}$, husillo RV4, velocidad de 0,01 a $100 \mathrm{rpm}$, reportándose la viscosidad a una velocidad de $100 \mathrm{rpm}$ [10]. Se utilizó un diseño factorial completamente aleatorizado de tres factores evaluados a dos niveles. Se realizaron dos réplicas del diseño. Se evaluó el efecto del pelado (pelada y sin pelar), el pH (4,0 y 5,0), y actividad enzimática de la mezcla de enzimas (nivel 1: Accellerase® 1500 $14,82 \mathrm{CMC} U / \mathrm{g}$ yuca fresca, Optimash TBG 33,82 $\mathrm{U} / \mathrm{g}$ yuca fresa y Pectinex Ultra 28,46 PECT U/g yuca fresa y nivel 2, cinco veces la actividad del nivel 1) sobre la viscosidad. Se expresó la actividad por gramos de yuca fresca con cáscara; para las suspensiones sin cáscaras se ajusta la actividad con el factor 1,1 que es la relación en base húmeda de peso de la masa de yuca con cáscara/ masa de yuca sin cáscara. Las unidades experimentales se mantuvieron en agitación a $150 \mathrm{rpm}$ en shaker orbital con control de temperatura a $60^{\circ} \mathrm{C}$. La viscosidad de las unidades experimentales fueron medidas después de dos horas de hidrólisis usando el reómetro a la temperatura de $25^{\circ} \mathrm{C}$. Como control fueron determinadas las viscosidades de suspensiones de yuca con y sin cáscara a concentraciones de 15 y $25 \%$ p/v. La viscosidad como variable respuesta fue analizada utilizando la técnica del ANOVA con la ayuda del software Desing Expert V 11

\subsection{Prelicuado de la masa de yuca hidrolizada con enzimas degradantes de la pared celular}

Las suspensiones de yuca fresca a una concentración de 15\% p/v de almidón hidrolizadas a las condiciones seleccionadas en la fase de reducción de viscosidad fueron llevadas a $64 \stackrel{\circ}{\mathrm{C}}$ y 150 rpm. Se adicionó el complejo enzimático Stargen® 001 (40 AGU/g almidón). El tiempo del proceso de prelicuado fue de 2 horas, tiempo que se recomienda antes de iniciar un proceso de hidrolisis y fermentación simultáneas con el objetivo que la levadura disponga de una cantidad mínima de azucares fermentables para garantizar su metabolismo. Se determinaron los contenidos de azucares reductores a los 30 y 130 minutos. Con el propósito de identificar el comportamiento del proceso, se determinó la concentración de glucosa y AR a las 24 y 48 horas Las unidades experimentales fueron Erlenmeyer de $250 \mathrm{ml}$ con un volumen de sistema de $150 \mathrm{ml}$. Los azucares reductores fueron 
evaluados utilizando el método DNS (método del ácido dinitrosalisilico propuesto por Miller [11]. La concentración de glucosa se determinó siguiendo la metodología descrita por Nguyen y otros (2014) [12]

\subsection{Hidrólisis y fermentación simultáneas}

Después de verificar la producción de azucares reductores por efecto de la hidrolisis de los gránulos de almidón se procedió a desarrollar la estrategia de proceso hidrolisis enzimática y fermentación simultánea; en esta etapa se evaluó el efecto del inóculo de la levadura y la actividad enzimática del complejo Stargen® 001 sobre la concentración de etanol en el proceso. El sistema fue ajustado a la temperatura de $37^{\circ} \mathrm{C}$ y el pH a 5,3. El inóculo de la levadura Ethanol Red y el complejo Stargen $\circledast 001$ fueron adicionados según la estrategia experimental bajo un diseño central compuesto rotable $(\alpha=1,41)$ de dos factores a dos niveles: Inóculo $(0,75$ y 2,25 g/L), carga enzimática del complejo Stargen ${ }^{\circledR} 001$ (40 y 90 AGU/g almidón).

Tabla 1. Diseño experimental para la evaluación de etanol en sistema HEFS

$\begin{array}{cccc}\text { Corrida } & \begin{array}{c}\text { Tipo } \\ \text { análisis }\end{array} & \begin{array}{c}\text { Factor 1 } \\ \text { A:Inoculo g/l }\end{array} & \begin{array}{c}\text { Factor 2 } \\ \text { B:Actividad } \\ \text { AGU/g }\end{array} \\ 1 & \text { Central } & 1,5 & 65 \\ 2 & \text { Factorial } & 0,75 & 90 \\ 3 & \text { Central } & 1,5 & 65 \\ 4 & \text { Axial } & 2,56066 & 65 \\ 5 & \text { Central } & 1,5 & 65 \\ 6 & \text { Factorial } & 2,25 & 90 \\ 7 & \text { Axial } & 0,43934 & 65 \\ 8 & \text { Central } & 1,5 & 65 \\ 9 & \text { Axial } & 1,5 & 100,355 \\ 10 & \text { Central } & 1,5 & 65 \\ 11 & \text { Factorial } & 0,75 & 40 \\ 12 & \text { Axial } & 1,5 & 29,6447 \\ 13 & \text { Factorial } & 2,25 & 40\end{array}$

Las unidades experimentales fueron frascos de 250 $\mathrm{ml}$ agitados a $150 \mathrm{rpm}$ en shaker orbital con un volumen de $150 \mathrm{ml}$ con control de temperatura y agitación. La concentración de etanol fue monitoreada a las 24,48 y 72 horas de proceso. La concentración de etanol se analizó por HPLC utilizando un detector IR y una columna Aminex HPX87H [13].Las variables de respuesta fueron analizadas utilizando la técnica de ANOVA. Se utilizó el software Desing Expert para realizar optimización del proceso. Se validaron las condiciones óptimas de operación en biorreactor Sartorius ${ }^{\circledR}$ de 3 litros de volumen útil, la validación se realizó por duplicado.

\section{RESULTADOS Y DISCUSIÓN}

\subsection{Caracterización de la yuca}

En la tabla 2 se presenta la caracterización de la yuca (parénquima y cáscara). La relación de la masa de la cáscara a la masa de parénquima fue de 0,208 g cáscara/g parénquima.

Tabla 2. Caracterización de la masa de yuca

\begin{tabular}{|c|c|c|}
\hline Parámetros & Cáscara & Parénquima \\
\hline Humedad & $71,1 \%$ & $57 \%$ \\
\hline Cenizas & $0,91 \%$ & $0,81 \%$ \\
\hline Proteína & $7 \%$ & $2,4 \%$ \\
\hline Almidón BS & $79,4 \%$ & $57,7 \%$ \\
\hline
\end{tabular}

Se destacó el alto valor proteico que se encontró en la cáscara del tubérculo, muy superior al valor que se identificó en el parénquima; los valores de proteína que se determinaron en los tubérculos de la yuca cuando se utilizan los chips de yuca o harina de yuca han sido reportados como suficientes para soportar las necesidades de nitrógeno de las levaduras en los procesos de fermentación alcohólica por lo que no fue necesario suplementar el medio de fermentación con una fuente de nitrógeno [14]. El almidón representó el $79,4 \%$ de la materia seca presente en la cáscara, un valor interesante para la valoración industrial de esta parte del tubérculo, interesante para alimentación animal al complementar el $7 \%$ de proteína, o sustrato para procesos de producción de etanol de primera o segunda generación [15]. Lo determinación de humedad, contenido de cenizas, proteína y almidón del parénquima estuvo en correspondencia con caracterizaciones hechas por otros investigadores, mostrando las bondades del tubérculo de la yuca como materia prima para la industria biotecnológica [1].

3.2 Evaluación de la reducción de viscosidad de las suspensiones de yuca 
Se presenta en la tabla 3 los resultados de evaluación de la viscosidad de las suspensiones de yuca al 15 y $25 \%$ p/v de almidón, utilizando yuca pelada y sin pelar. Se observó, como era de esperarse desde la reologia de suspensiones que la viscosidad fue mayor para las suspensiones preparadas al 25\% p/v de almidón; el efecto del pelado en la yuca como materia prima para la preparación de las suspensiones también tuvo un marcado efecto sobre la viscosidad para las dos concentraciones evaluadas, las suspensiones elaboradas con yuca sin pelar presentaron mayores viscosidades que las suspensiones elaboradas con yuca pelada; esto se debió al efecto que presentan las fibras en la reologia de las suspensiones presentes mayoritariamente en la cáscara que en el parénquima de éste tubérculo. El ANOVA mostró que los factores concentración de almidón en la suspensión y la presencia de cáscara presentaron significancia estadística sobre la viscosidad de la suspensión $(p<0,05, p=0,1245$ para presencia de cáscara y $p=0,0088$ concentración de almidón).

Tabla 3. Viscosidad de las suspensiones de yuca fresa a $25^{\circ} \mathrm{C}$ y pH 5.0

\begin{tabular}{|c|c|c|}
\hline $\begin{array}{c}\text { Almidón } \\
\% \mathrm{p} / \mathrm{v}\end{array}$ & $\begin{array}{c}\text { Presencia } \\
\text { de cáscara }\end{array}$ & $\begin{array}{c}\text { Viscosidad } \\
\mathrm{cP}\end{array}$ \\
\hline 15 & Sin & $48,5 \pm 5,3$ \\
\hline 15 & Con & $170,2 \pm 8,1$ \\
\hline 25 & Sin & $203,6 \pm 4,8$ \\
\hline 25 & Con & $328,1 \pm 6,7$ \\
\hline
\end{tabular}

Los valores de viscosidad reportados en la tabla 2 fueron tomados como referencia para validar el efecto reductor de viscosidad por efecto de la mezcla enzimática utilizada.

En tabla 4 se observan los valores de viscosidad obtenidos al evaluar el efecto del pelado del tubérculo, el $\mathrm{pH}$, y la actividad enzimática sobre la viscosidad de las suspensiones de yuca al $15 \% \mathrm{p} / \mathrm{v}$. Las suspensiones al $25 \% \mathrm{p} / \mathrm{v}$ de almidón presentaron problemas de mezclado de las enzimas en la suspensión en los erlenmeyer, presentando éstas una textura pastosa, razón por la cual las pruebas a esta concentración fueron descartadas.
Tabla 4. Valores de viscosidad de la suspensiones de yuca sometidos al diseño experimental $(15 \% \mathrm{p} / \mathrm{v}$ almidón)

\begin{tabular}{|c|c|c|c|}
\hline $\mathrm{PH}$ & Enzima & Pelado & Viscosidad cP \\
\hline 5 & -1 & -1 & 0,930 \\
\hline 4 & -1 & 1 & 0,660 \\
\hline 4 & -1 & -1 & 0,692 \\
\hline 5 & 1 & 1 & 0,554 \\
\hline 4 & 1 & 1 & 0,497 \\
\hline 5 & -1 & 1 & 0,558 \\
\hline 5 & 1 & -1 & 0,652 \\
\hline 4 & 1 & -1 & 0,636 \\
\hline 5 & 1 & -1 & 0,942 \\
\hline 4 & 1 & -1 & 0,639 \\
\hline 4 & -1 & -1 & 0,867 \\
\hline 4 & -1 & 1 & 0,641 \\
\hline 4 & 1 & 1 & 0,639 \\
\hline 5 & 1 & 1 & 0,782 \\
\hline 5 & -1 & -1 & 1,248 \\
\hline 5 & -1 & 1 & 0,914 \\
\hline
\end{tabular}

Todos los factores evaluados presentaron efecto significativo sobre la reducción de viscosidad $(p<$ 0,05 ); el $\mathrm{pH}$ y el efecto del pelado presentaron los mayores efectos, ninguna de las interacciones entre factores presentó efecto sobre la variable respuesta (ver tabla 5). El $\mathrm{R}^{2}$ ajustado arrojó un valor de $74,29 \%$.

Tabla 5. Anova de la variable viscosidad

\begin{tabular}{|c|c|c|c|c|c|}
\hline Fuente & $\begin{array}{c}\text { Suma de } \\
\text { Cuadrados }\end{array}$ & GI & $\begin{array}{c}\text { Cuadrado } \\
\text { Medio }\end{array}$ & Razón-F & Valor-P \\
\hline $\mathrm{pH}$ & 0,10709 & 1 & 0,10709 & 4,13 & 0,0265 \\
\hline Enzima & 0,08541 & 1 & 0,08541 & 3,29 & 0,0471 \\
\hline Pelado & 0,11577 & 1 & 0,11577 & 4,46 & 0,0376 \\
\hline $\mathrm{AB}$ & 0,00459 & 1 & 0,00459 & 0,18 & 0,6851 \\
\hline $\mathrm{AC}$ & 0,02009 & 1 & 0,02009 & 0,77 & 0,4045 \\
\hline $\mathrm{BC}$ & 0,02009 & 1 & 0,02009 & 0,77 & 0,4045 \\
\hline $\mathrm{ABC}$ & 0,00676 & 1 & 0,00676 & 0,26 & 0,6234 \\
\hline Residuo & 0,20755 & 8 & 0,02594 & & \\
\hline $\begin{array}{c}\text { Total } \\
\text { (corregido) }\end{array}$ & 0,56736 & 15 & & & \\
\hline
\end{tabular}

Del análisis de las tablas 3 y 4 se observó una drástica reducción en la viscosidad de las suspensiones pasando de valores de suspensiones 
al $15 \% \mathrm{p} / \mathrm{v}$ de almidón partiendo de yuca sin pelar y pelada de 170,2 y 48,5 cP respectivamente, a valores ligeramente inferiores a $1 \mathrm{cP}$, pasando de comportamientos de las suspensiones muy viscosas a suspensiones muy fluidas, con baja resistencia a fluir sin presentar impedimentos de homogenización en el shaker orbital; este comportamiento se explica por el efecto del papel que juegan las enzimas utilizadas, ya que estas presentan actividades endoglucanasa, exoglucanasa, $\beta$ glucosidasa y pectinasas, actuando sobre los biopolímeros de las fibras de la masa de la yuca en suspensión: celulosa, hemicelulosa y pectina.

Se observó correspondencia del comportamiento con los hallazgos usando enzimas con actividades endoglucanasa, celulasa, pectinasa y xillansas en el proceso de producción de etanol a partir de suspensiones de yuca, en éste estudio se identificó el comportamiento pseudoplástico de las suspensiones y también se lograron reducciones de viscosidad hasta $1.01 \mathrm{cP}$, partiendo de suspensiones con viscosidades iniciales de $832 \mathrm{cP}$ en pastas de $32 \% \mathrm{p} / \mathrm{v}$ de sólidos después de 2 horas de tratamiento enzimático a $65^{\circ} \mathrm{C}$ [16]. Los valores mayores de viscosidad al inicio se explican en mayores concentraciones del almidón al iniciar el proceso. Se han realizado ahorros de energía en el proceso de producción de etanol a partir de patata dulce mediante el uso de xilanasas con actividades de $1,56 \mathrm{AGU} / \mathrm{g}$ a $44,1^{\circ} \mathrm{C}$ y $87,6 \mathrm{~min}$ de hidrolisis, reduciendo la viscosidad a 498,1 cP [4], en nuestro estudio se atribuye una mayor reducción de viscosidad al uso de una mezcla de enzimas con diferentes y mayores actividades enzimáticas, además de una menor concentración de almidón en la suspensión.

Las bondades de uso de cocteles de enzimas con diferentes actividades hidrolíticas sobre carbohidratos estructurales y polímeros de la pared celular con actividaddes $\beta$-glucosidasa, endoglucanasa, exoglucanasa, xylanasas, and pectinasas fueron reportadas por Poonsrisawat et al. 2014 [16]; 2016 [17]. Las limitaciones de la alta viscosidad para la extracción de los gránulos de almidón y el acceso de las moléculas del agua por efecto de la matriz pectina-hemicelulosa explican los resultados en la reducción de viscosidad por el uso de las enzimas hidrolizantes de la pectina y la hemicelulosa y están en correspondencia con el uso de enzimas con estas actividades en la producción de etanol a partir de tubérculos frescos y almidón de yuca [2]. El uso de los complejos enzimáticos con diferentes actividades hidrolíticas aumenta la hidrolisis del almidón resistente y reducen la viscosidad de la suspensión [16]

Para los niveles de $\mathrm{pH}$ evaluados en la reducción de viscosidad si bien se presentó diferencia significativa desde el punto de vista estadístico, a nivel práctico no habría diferencia frente al nivel de viscosidad alcanzada. A pH de 4 se alcanzó una menor viscosidad, valor de $\mathrm{pH}$ diferente a los valores de $\mathrm{pH}$ de máxima actividad reportada para las enzimas utilizadas (4,6 para Accelerase ${ }^{\circledR} 1500$, 5,0 para Optimash y 4,5 para Pectinex ultra); esto se vio compensado por la actividad enzimática usada en la experimentación, ya que como se esperaba se observó una mayor reducción de la viscosidad para el nivel 2 del uso de la mezcla enzimática correspondiente a 5 veces la actividad utilizada en el nivel1.

Se seleccionaron como mejores condiciones de proceso de reducción de viscosidad: yuca sin pelar, el nivel 1 de actividad enzimática de la mezcla de enzimas y el $\mathrm{pH}$ de 5,0, que es el nivel de mayor actividad catalítica de la enzima Accelerase ${ }^{\circledR} 1500$ y muy próximo al pH de la suspensión de la yuca.

\subsection{Prelicuado de la masa de yuca hidrolizada con enzimas degradantes de la pared celular}

En la tabla 6 se observa el valor de los azucares reductores producidos en la etapa de prelicuado a los 15, 30 y 130 minutos de proceso de acción de la enzima hidrolizante de almidón granular (Stargen®) 001) a $64{ }^{\circ} \mathrm{C}$ y pH 5.0 .

Tabla 6. Producción de azúcares reductores en el proceso de prelicuado

\begin{tabular}{|c|c|c|c|c|}
\hline $\begin{array}{c}\text { Tiempo } \\
\text { (min) }\end{array}$ & 0 & 15 & 30 & 130 \\
\hline $\begin{array}{c}\text { Azucares } \\
\text { reductores } \\
(\mathrm{g} / \mathrm{l})\end{array}$ & $29 \pm 0,7$ & $30 \pm 0,7$ & $45 \pm 2,5$ & $82 \pm 0,4$ \\
\hline
\end{tabular}

Al inicio del proceso de prelicuado se partió con una concentración de $29 \mathrm{~g} / \mathrm{l}$ de AR, que provenían de los productos de la hidrolisis de la mezcla de enzimas reductoras de viscosidad, que por tener actividad endoglucanasa, exoglucanasa, $\beta$ glucanasa y pectinestearasa liberaron azucares con capacidad 
reductora al medio. En los primeros 15 minutos no se apreció un cambio en el contenido de AR; el incremento se presentó para los 30 y 130 minutos, en donde se alcanzaron concentraciones de AR de 45 y $82 \mathrm{~g} / \mathrm{l}$ de $A R$, lo que demuestra la eficacia del complejo enzimático stargen $\circledast 001$ como mix enzimático hidrolítico de almidón granular. Similares resultados en la obtención de azucares reductores en la etapa de prelicuado fueron obtenidos en el proceso HEFS de harina de yuca [17], gracias al efecto sinérgico que desarrollaron las enzimas alfa amilasa y glucoamilasa que hidrolizaron el almidón granular en glucosa, sin requerir los procesos de cocción del granulo para que se desarrolle en el proceso de gelatinización y la liberación al medio de las moléculas de amilosa y amilopectina.Se reportan en la tabla 6 la concentración de AR y glucosa obtenidas por efecto de la hidrolisis para las 24 y 48 horas en suspensiones de yuca con y sin cáscara al $15 \%$ p/v de concentración de almidón a pH 5.0 y 60 ${ }^{\circ} \mathrm{C}$

Tabla 7. Azucares reductores y glucosa a 24 y $48 \mathrm{~h}$ de hidrolisis con el complejo de enzima Stargen ${ }^{\circledR}$ 001

\begin{tabular}{|c|c|c|c|c|}
\hline & \multicolumn{2}{|c|}{ Sin cáscara } & \multicolumn{2}{c|}{ Con cáscara } \\
\hline $\begin{array}{c}\text { Tiempo } \\
(\mathrm{h})\end{array}$ & 24 & 48 & 24 & 48 \\
\hline AR $(\mathrm{g} / \mathrm{l})$ & $184,7 \pm$ & 181,8 & $173,7 \pm$ & 204,9 \\
& 0,5 & $\pm 0,0$ & 2,6 & $\pm 1,13$ \\
\hline Glucosa & $129,4 \pm$ & $156 \pm$ & $137 \pm$ & $168 \pm$ \\
$(\mathrm{g} / \mathrm{l})$ & 1,4 & 4,1 & 3,6 & 0,7 \\
\hline
\end{tabular}

Para las 24 horas se observó una mayor liberación de AR para el sistema en el que se peló la yuca, esto se puede explicar en impedimentos hidrodinámicos por la presencia de fibra en la suspensión elaborada sin remover la cáscara. La concentración de AR y glucosa para los dos sistemas a las 24 y 48 horas mostró muy poca variación, el porcentaje grande de la hidrolisis se realizó en las primeras 24 horas de proceso, condición favorable para la etapa posterior que se evaluó: hidrolisis enzimática y fermentación simultánea, que garantiza que la hidrolisis aunque sea la etapa controlante en la integración simultanea de procesos, proveerá la cantidad necesaria del glucosa a la levadura por encima de concentraciones críticas. Los valores de glucosa obtenidos al final representaron valores de rendimiento de conversión de almidón en glucosa del $91 \%$, valor de rendimiento mayor a los reportados por Cardona y otros (69\%)
[18] que demuestran la eficacia del complejo enzimático para desdoblar el almidón en glucosa a partir de yuca fresca [19].

\subsection{Hidrólisis y fermentación simultáneas}

En la tabla 8 se presentan los resultados de la producción de etanol en el proceso de hidrolisis enzimática y fermentación simultánea a partir de yuca fresca usando enzimas degradantes de la pared celular y enzimas que hidrolizan los gránulos de almidón. Para las condiciones evaluadas se observó una producción de etanol entre 53,04 y $81,97 \mathrm{~g} / \mathrm{l}$ que correspondieron a rendimientos $\mathrm{Yp} / \mathrm{s}$ de 0,32 y $0,49 \mathrm{~g}$ etanol $/ \mathrm{g}$ glucosa y rendimiento globales de $62 \% \quad\left((0,32 / 0,51)^{*} 100\right)$ y $96 \%$ $\left((0,49 / 0,51)^{\star} 100\right)$ frente al valor teórico de rendimiento de $0,51 \mathrm{~g}$ etanol $/ \mathrm{g}$ glucosa respectivamente.

Tabla 8. Diseño experimental, concentración de etanol a las $72 \mathrm{~h}$ y rendimientos de etanol

\begin{tabular}{|c|c|c|c|c|c|}
\hline Corrida & $\begin{array}{c}\text { Inoculo } \\
\text { g/l }\end{array}$ & $\begin{array}{c}\text { Actividad } \\
\text { enzimática } \\
\text { AGU/g } \\
\text { almidón }\end{array}$ & $\begin{array}{c}\text { Etanol } \\
\text { g/L }\end{array}$ & $\begin{array}{c}\text { Yp/s g } \\
\text { etanol } \\
\text { /g } \\
\text { glucosa }\end{array}$ & $\begin{array}{c}\text { Rendimiento } \\
\text { (Yp/sexp/Yps } \\
\text { teórico })\end{array}$ \\
\hline 1 & 1,5 & 65 & 74,94 & 0,45 & 88,06 \\
\hline 2 & 0,75 & 90 & 65,73 & 0,39 & 76,32 \\
\hline 3 & 1,5 & 65 & 73,12 & 0,44 & 86,11 \\
\hline 4 & 2,56 & 65 & 81,97 & 0,49 & 95,89 \\
\hline 5 & 1,5 & 65 & 79,38 & 0,48 & 93,93 \\
\hline 6 & 2,25 & 90 & 70,2 & 0,42 & 82,19 \\
\hline 7 & 0,44 & 65 & 63,84 & 0,38 & 74,36 \\
\hline 8 & 1,5 & 65 & 76,13 & 0,46 & 90,02 \\
\hline 9 & 1,5 & 100,3 & 73,69 & 0,44 & 86,11 \\
\hline 10 & 1,5 & 65 & 73 & 0,44 & 86,11 \\
\hline 11 & 0,75 & 40 & 62,12 & 0,37 & 72,41 \\
\hline 12 & 1,5 & 29,7 & 53,04 & 0,32 & 62,62 \\
\hline 13 & 2,25 & 40 & 72,12 & 0,43 & 84,15 \\
\hline
\end{tabular}

Tabla 9. Análisis de varianza de la producción de etanol en sistema HEFS 


$\begin{array}{ccccccc}\text { Variable } & \begin{array}{c}\text { Suma } \\ \text { de } \\ \text { cuadra } \\ \text { dos }\end{array} & \begin{array}{c}\text { Grados } \\ \text { de }\end{array} & \begin{array}{c}\text { Cuadra } \\ \text { do }\end{array} & \begin{array}{c}\text { Razón } \\ \text { medio }\end{array} & \text { Falor P } \\ \text { Modelo } & 564,75 & 5 & 112,95 & 5,62 & 0,021^{*} \\ \text { A-Inoculo } & 201,10 & 1 & 201,10 & 10,01 & 0,015^{*} \\ \text { B-Enzimas } & 119,30 & 1 & 119,30 & 5,94 & 0,045^{*} \\ \text { AB } & 7,65 & 1 & 7,65 & 0,380 & 0,556 \\ A^{2} & 7,75 & 1 & 7,75 & 0,385 & 0,554 \\ B^{2} & 236,09 & 1 & 236,09 & 11,75 & 0,010^{*} \\ \text { Residual } & 140,64 & 7 & 20,09 & & \\ \begin{array}{c}\text { Falta de } \\ \text { ajuste }\end{array} & 110,92 & 3 & 36,97 & 4,98 & 0,176 \\ \text { Error puro } & 29,72 & 4 & 7,43 & & \\ \text { Total } & & & & & \\ \text { corregido } & 705,39 & 12 & & & \end{array}$

Fuente: Software Desing Expert V. 11 ( ${ }^{*}$ variables significativas)

El análisis de varianza arrojó que para los niveles evaluados de inóculo y carga del complejo hidrolizante de almidón en forma granular presentaron efecto significativo sobre la producción de etanol $(p \leq 0,05)$. Se presentó un mayor efecto sobre la producción de etanol de la carga del microorganismo, lo que significa que el proceso de hidrolisis granular de almidón a glucosa no limitó el proceso fermentativo (ver tabla 9). El modelo presentó un ajuste $\left(R^{2}=0,81\right.$ y $R^{2}$ ajustado $\left.=0,67\right)$, además el modelo presentó falta de ajuste no significativa. En la figura 1 se muestra la superficie de respuesta de la concentración de etanol, se identificaron las condiciones de proceso para la obtención de mayor conversión a etanol: inóculo $2,25 \mathrm{~g} / \mathrm{l}$ y una actividad superior a $60 \mathrm{AGU} / \mathrm{g}$. El modelo matemático ajustado de los datos experimentales se presenta en la ecuación (1):

Etanol $\left(\frac{g}{l}\right)=3,8595+17,107 A+1,47 B-0,009 B *$ $B \quad(1)$

Los mayores valores de concentración de etanol se obtuvieron en la región de alta concentración de inóculo y de alta actividad enzimática. El mayor valor del coeficiente de la ecuación para el inóculo muestra su mayor efecto sobre la producción de etanol, y corresponde al metabolismo anaerobio de la levadura; mientras que el menor coeficiente y menor significancia estadística (mayor p-value) se explica en la menor complicación del proceso de hidrolisis enzimática frente al proceso de producción de etanol por parte de la levadura; además muestra que en el proceso de hidrólisis enzimática y fermentación simultánea, la hidrolisis del almidón en azucares fermentables no fue la etapa controlante, lo que se buscaba y se garantizó con el proceso de prelicuado antes de iniciar el proceso HEFS.

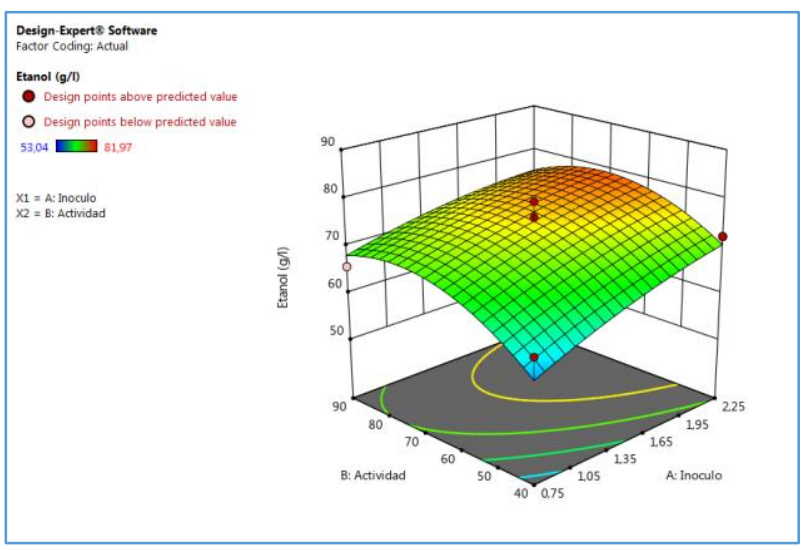

Figura 1. Superficie de respuesta de la concentración de etanol como función de la actividad enzimática y el inóculo

\subsection{Optimización y escalamiento en biorreactor de 3 litros}

Se utilizó el software Desing Expert para realizar la optimización del proceso, se tomó como criterio la maximización de la concentración de etanol (ecuación (1)); y se mantuvieron en el intervalo los valores de inóculo y actividad del complejo Stargen® 001 usando la función de deseabilidad [20]. Se obtuvo un valor se la función de deseabilidad de 0,91 para las siguientes condiciones: inóculo de 2,25 g/l de levaduras y una actividad del complejo y Stargen® 001 de 70,65 AGU/g almidón, y una concentración de etanol esperada de 79,22 g/l (ver tabla 9). Estas condiciones fueron validadas en el biorreactor de 3 litros y se alcanzaron a las 72 horas concentraciones de 78,5 y $85,16 \mathrm{~g}$ etanol// para las dos replicas, lo que representó rendimientos de 92 y $100 \%$ respectivamente. El incremento en el porcentaje de rendimiento se pudo soportar en las mejores condiciones de mezclado en el biorreactor (sistema mecánico) vs la agitación orbital en el Shaker, favoreciendo una mejor mezcla y homogeneidad en el sistema, lo mismo que un mejor 
control de las condiciones de proceso como temperatura y $\mathrm{pH}$.

Tabla 9. Resultados de optimización y escalamiento del proceso en biorreactor de 3 litros

\begin{tabular}{|c|c|c|c|c|}
\hline \multirow{2}{*}{$\begin{array}{c}\text { Tiempo } \\
\text { (h) }\end{array}$} & \multicolumn{2}{|c|}{ Replica 1 } & \multicolumn{2}{c|}{ Replica 2 } \\
\cline { 2 - 5 } & $\begin{array}{l}\text { Glucosa } \\
\text { (g/l) }\end{array}$ & $\begin{array}{l}\text { Etanol } \\
\text { (g/l) }\end{array}$ & $\begin{array}{l}\text { Glucosa } \\
(\mathbf{g} / \mathbf{l})\end{array}$ & Etanol (g/l) \\
\hline 0 & 0.51 & 0.00 & 1,57 & 0.00 \\
\hline 24 & 30.54 & 12.06 & 23.32 & 10.57 \\
\hline 48 & 30.81 & 72.58 & 60.50 & 68.78 \\
\hline 72 & 12.15 & 78,50 & 8.06 & 85.16 \\
\hline
\end{tabular}

\section{CONCLUSIONES}

Se pudo desarrollar el proceso de producción de etanol a partir de yuca fresca experimentalmente el efecto que tiene el uso de enzimas degradantes de la pares celular sobre la reducción de la viscosidad de las masas de yuca peladas y sin pelar. El pH del medio, la cantidad de enzima utilizada y la presencia de cáscara en la yuca afectan la reducción de viscosidad de las masas de yuca. La reducción de viscosidad de las masas de yuca provee un sistema adecuado para la acción de las enzimas del complejo Stargen $\AA^{\circledR} 001$ para realizar la hidrolisis de los gránulos de almidón. Fue posible integrar los procesos de hidrolisis y fermentación simultáneos en la producción de etanol a partir de yuca fresca, en esta etapa tanto la carga enzimática del complejo Stargen ${ }^{\circledR}$ 001, como la cantidad de inoculo presentaron efecto sobre la producción de etanol. Fue posible validar experimentalmente las condiciones de proceso obtenidas por optimización del proceso, se alcanzaron concentraciones de etanol de $85 \mathrm{~g} / \mathrm{l}$ que equivalen a rendimientos del $100 \%$. Es posible producir etanol mediante la estrategia de proceso HEFS usando enzimas degradantes de la pared celular, que permiten la reducción de la viscosidad de las suspensiones de yuca; y el uso de enzimas que hidrolizan los gránulos de almidón sin la necesidad de realizar el proceso a condiciones convencionales de licuefacción (temperaturas mayores a $90^{\circ} \mathrm{C}$ ).

\section{AGRADECIMIENTOS}

El autor del artículo agradece el apoyo económico y administrativo brindado por la dirección de Investigación y Posgrados del Politécnico Jaime Isaza Cadavid para la ejecución del proyecto inscrito en la línea matriz de ambiente y sostenibilidad

\section{REFERENCIAS BIBLIOGRÁFICAS}

[1] Ospina, B. y Ceballos, H. La yuca en el tercer Milenio: Sistemas Modernos de producción, procesamiento, utilización y comercialización. CIAT. Cali, 2002.

[2] Wichitchan, C. y, Skolpap, W. Optimum cost for ethanol production from cassava roots and cassava chips, Energy Procedia., 52, 190 - 203, 2014.

[3] Rutz, D. y Janssen, R. Biofuel technology handbook. Munich: WIP Renewable Energies; 2007. [4] Zhang, L., Zhao, H., Gan, M., Jin , Y., Gao, X., Chen, Q., Guan, F., y Wang, Z. Application of simultaneous saccharification and fermentation (SSF) from viscosity reducing of raw sweet potato for bioethanol production at laboratory, pilot and industrial scales, Bioresorces Technology., 102, 4573-4579, 2011.

[5] Sriroth, K. y Piyachomkwan, K. Processing of Cassava into Bioethanol. Proceedings of 8th Regional Workshop: A New Future for Cassava in Asia: Its Use as Food, Feed and Fuel to benefit the poor, pp. 740-750, Vientiane, Lao PDR, Oct 20-24, 2008.

[6] Beldman, G., Rombouts, F.M., Voragen, A.G.J., Pilnik, W. Application of cellulase and pectinase from fungal origin for the liquefaction and saccharification of biomass, Enzyme Microb Technol., 6, 503-7, 1984.

[7] Slominska, L., Starogardzka, G., Application of a multi-enzyme complex in the utilization of potato pulp, Starch-Starke., 39, 121-5, 1987.

[8] A.O.A.C.1990. Official methods of analysis. Association of official Analytical Chemist. E.U.A.

[9] Mestres, C. Comparison of various processes of making maize pasta, J. Cereal Sci., 17, 277 - 290, 1993.

[10] Mirhosseini, H., Tan, C. P., Hamid, N. S. A, \& Yusof, S. Effect of Arabic gum, xanthan gum and orange oil contents on $\zeta$-potential, conductivity, stability, size index and $\mathrm{pH}$ of orange beverage emulsion, Colloid Surface A: Physicochem Eng Asp., 315, 47-56, 2008.

[11] Miller, G. Use of dinitrosalicylic acid reagent for determination of reducing sugar, Anal.Chem., 31, 426-428, 1959. 
[12] Nguyen,C-N., Le, T-M., Chu-Ky, S. Pilot scale simultaneous saccharification and fermentation at veryhigh gravity of cassava flour for ethanol production, Industrial crops and products, 56, 160165, 2014.

[13] Castaño, H.I, Mejía, C.E., Producción de etanol a partir de almidón de yuca utilizando la estrategia de proceso sacarificación- Fermentación simultáneas SSF, Vitae., 15, 51-58, 2008.

[14] Esquivia, M, Castaño, H., Atehortúa, L., Acosta, A., y Mejia, C. Producción de etanol a partir de yuca en condiciones de alta concentración de sólidos (VHG), Revista Colombiana de Biotecnología, 16 (1), 163-170, 2014.

[15] Castaño, H., Reales, J. y Zapata, J. Enzymatic hydrolysis of cassava stalk pretreated with the alkaline method, Agronomía Colombiana., 33 (2), 238-243, 2015.

[16] Poonsrisawat, A., Wanlapatit, S., Paemanee, A., Eurwilaichitr, L., Piyachomkwan, K., and Champreda, V. Viscosity reduction of cassava for very high gravity ethanol fermentation using cell wall degrading enzymes from Aspergillus aculeatus, Process Biochem., 49 (11), 1950-1957. 2014. DOI: $10.1016 /$ j.procbio.2014.07.016

[17] Poonsrisawat, A., Wanlapatit, S., Wansuksri, R., Piyachomkwan, K., Paemanee, A., Gamonpilas, C., Champreda, V. Synergistic effects of cell wall degrading enzymes on rheology of cassava root mash, Process Biochemistry, 7, 290,.2016 https://doi.org/10.1016/j.procbio.2016.09.010

[18] Castaño, H., Cardona, M., Mejía, C. y Acosta, A. Producción de etanol a partir de harina de yuca en un sistema de hidrólisis enzimática y fermentación simultánea, Dyna., 169, 158-166, 2011.

[19] Pradyawong, S., Juneja, A., Bilal Sadiq,M., Noomhorm , A y Singh, V. Comparison of Cassava Starch with Corn as a Feedstock for Bioethanol Production, Energies., 11, 3476-3487, 2018. https://doi.org/10.3390/en11123476

[20] Castaño, E. y Domínguez, J. "Diseño de experimentos: Estrategias y análisis en ciencia y tecnología". Universidad Autónoma de Querétaro, Querétaro, México, 2010. 